\title{
SEVERAL DIMENSIONS, ANTHROPOMETRIC INDICES AND NUTRITIONAL CONDITION OF FRESHMEN IN HANOI MEDICAL UNIVERSITY, YEAR 2019-2020
}

\author{
Ngo Xuan Khoa*, Le Gia Vinh **, Tran Quang Huy*, \\ Nguyen Tuan Son ${ }^{\star \star \star}$, Nguyen Thai Ha Duong ${ }^{\star \star \star}$, Ngo Huong Giang ${ }^{\star \star \star \star}$
}

\section{ABSTRACT}

Our aim is to describe the morphology, physical and nutritional status of Vietnamese medical students in the late years of second decade of the $21^{\text {th }}$ Centery. A research about physical form included 861 freshmen (335 male, 526 female) from Hanoi Medical University (2019 - 2020): Male students' physical form measurement and figures are much better than female students' and these indices is largely better than the previous studies of other authors. Physical form seems to increase by the time, after 45 years: male was $9.5 \mathrm{~cm}$ higher and $15.9 \mathrm{~kg}$ heavier, female was $7.0 \mathrm{~cm}$ higher and $5.8 \mathrm{~kg}$ heavier. In comparison with students in 2007, male students were $8.5 \mathrm{kgs}$ heavier and female students were $3.9 \mathrm{kgs}$ heavier. In comparison with a research ten years ago, the height of male and female increased $4.2 \mathrm{~cm}$ and $3.3 \mathrm{~cm}$, respectively. According to an Asian - Pacific population classification, students from Hanoi Medical University had medium weight.

Key words: Physical form; Medical Students.

\footnotetext{
* Hanoi Medical University

** Vietnam Medical Association

*** University of Medicine and Pharmacy -

Vietnam National University, Hanoi

**** High School for Gifted Students -

University of Natural Sciences - Vietnam

National University, Hanoi

Responsible person: Ngo Xuan Khoa

Email: ngoxuankhoavn@gmail.com

Date of receipt: $25 / 5 / 2021$

Date of scientific judgment: 01/07/2021

Reviewed date: $15 / 8 / 2021$
}

\section{INTRODUCTION}

The issue of morphological and physical development of university students is one of the central issues in the human development strategy and in the cause of education.

The morphological and physical development of humans is greatly influenced by genetic factors, as well as the living environment with continuous changes in socio-economic conditions and nutrition. Therefore, every 10 years or so: "the next generation is constantly higher than the previous generation" has become an inevitable law of development [9]. Since then, in order to have more accurate assessments of anthropometric morphology and physical and nutritional status in different historical periods, anthropometric studies were periodically and additionally conducted.

Particularly in terms of nutrition, although there are many new means of exploration, anthropometry is still the simplest, least expensive and widely applied assessment method to assess the nutritional status and composition of the human body.

Requiring synthesis of new reference standards is inevitable in the new decades. Therefore, in order to contribute to an accurate reflection of the morphology, physical condition and nutrition of Vietnamese adults, 
especially medical students in the second half of the second decade of the 21 st century, we conducted this study to: Assess the physical condition and survey the nutritional status of freshmen at Hanoi Medical University in the academic year 2019-2020.

\section{MATERIALS AND METHODS}

\section{Subjects}

861 first-year students Hanoi Medical University, including 335 males and 526 females in the 2019-2020 academic year.

\section{Research methods}

\subsection{Research content:}

Carrying out a cross-sectional survey on the dimensions, physical fitness index and nutrition of the first-year students at Hanoi Medical University in the academic year 2019-2020.

* Research dimensions and indicators:

-Morphological and physical dimensions: Standing height $(\mathrm{cm})$; Sitting height (cm); Weight $(\mathrm{kg})$; Waist circumference $(\mathrm{cm})$; Hip circumference (cm); Normal chest circumference (VNBT) (cm); chest circumference on forced inhalation $(\mathrm{cm})$; chest circumference on forced expiration $(\mathrm{cm})$; flexioning right arm circumference $(\mathrm{cm})$; left forearm circumference $(\mathrm{cm})$; right thigh circumference (cm); left calf circumference (cm); Thickness of subcutaneous fat in the right umbilicus, the posterior middle side of right arm and the inferior side of right shoulder(mm).
-Then calculating the indicators according to the formulas:

$>$ Pignet $=$ Standing height $(\mathrm{cm})-$ [Weight $(\mathrm{kg})+\operatorname{VNBT}(\mathrm{cm})]$.

$>$ BMI $=$ Weight $(\mathrm{kg}) /$ Standing height ${ }^{2}$ (m).

$>$ Body index $=$ Sitting height $(\mathrm{cm}) /$ Standing height $(\mathrm{cm}) \times 100$.

\subsection{Measuring Instruments:}

- Measure body circumference: Using a Chinese non-expanding plastic tape measure with an accuracy of $1 \mathrm{~mm}$. Results rounded to $0.5 \mathrm{~cm}$.

- Body weight measurement: Using Tanita electronic table scale with accuracy to $0.1 \mathrm{~kg}$. Results rounded to $0.5 \mathrm{~kg}$.

- Measure body height: Use Martin anthropometric scale with accuracy to 1 $\mathrm{mm}$. Results rounded to $0.5 \mathrm{~cm}$.

- Measuring the thickness of subcutaneous fat: Using Harpenden skinfold caliper compas, brand HOLTAIN - Switzerland with accuracy to $0.2 \mathrm{~mm}$. Results rounded to $0.5 \mathrm{~mm}$.

\subsection{Data analysis:}

- Calculate the indexes according to the formulas recorded above.

- Data analyzed using SPSS 16.0 and Excel office 2016 programs.

\section{RESULTS AND DISCUSSION}

1. Compare the morphological and physical dimensions, indicators between gender.

Table 1: The morphological and physical dimensions, indicators.

\begin{tabular}{|c|c|c|c|}
\hline Dimensions, indicators & Male (n= 335) & Female (n= 526) & p \\
\hline Weight & $60,96 \pm 9,61$ & $48,76 \pm 6,51$ & $<0,01$ \\
\hline Standing height & $168,47 \pm 5,73$ & $155,99 \pm 5,65$ & $<0,01$ \\
\hline
\end{tabular}


No 1\&2/2021 VIETNAM MEDICAL JOURNAL

\begin{tabular}{|c|c|c|c|}
\hline \hline Dimensions, indicators & Male (n= 335) & Female (n= 526) & $\mathbf{p}$ \\
\hline Sitting height & $90,93 \pm 3,77$ & $85,04 \pm 3,10$ & $<0,01$ \\
\hline Waist circumference & $75,62 \pm 8,20$ & $70,74 \pm 6,31$ & $<0,01$ \\
\hline VNBT & $80,17 \pm 6,87$ & $72,02 \pm 6,38$ & $<0,01$ \\
\hline Hip circumference & $89,24 \pm 6,17$ & $87,17 \pm 5,41$ & $<0,01$ \\
\hline Pignet & $27,34 \pm 14,27$ & $35,21 \pm 11,15$ & $<0,01$ \\
\hline BMI & $21,45 \pm 3,01$ & $20,03 \pm 2,39$ & $<0,01$ \\
\hline Body index & $53,98 \pm 1,67$ & $54,53 \pm 1,25$ & $<0,01$ \\
\hline
\end{tabular}

- The average weight, standing height, sitting height, waist circumference, hip circumference and normal chest circumference of men were significantly larger than that of women, the difference was statistically significant $(\mathrm{p}<0.01)$.

- The Pignet index of men and women has a significant difference, with statistical significance $(\mathrm{p}<0.01)$. According to the classification scale of Nguyen Quang Quyen et al., male students belong to the very physically strong category while female students belong to the average category.

- There is a difference in BMI of male students with statistical significance $(\mathrm{p}<$ 0.01). According to WHO classification standards for Asia-Pacific people, the physical strength and nutritional status of students at Hanoi Medical University are in the normal weight category.

- Body index of male and female students according to the classification scale is long body type, the difference was statistically significant $(p<0.01)$.

2. Dimensions and indicators for nutritional status survey

\subsection{Waist circumference}

Waist circumference reflects the accumulation of abdominal fat (including subcutaneous fat and fat around the abdominal viscera) also known as central fat. So, waist circumference has a lot of significance in nutritional assessment.
The average waist circumference of was $75.62 \pm 6.20 \mathrm{~cm}$ in male and $70.74 \pm 6.31 \mathrm{~cm}$ in female. The difference in waist circumference of the two sexes was statistically significant $(\mathrm{p}<0.01)$.

Compared with the biological value data of the average Vietnamese in the 90s of the $20^{\text {th }}$ century (was $66.14 \pm 4.5 \mathrm{~cm}$; female was $62.80 \pm 3.82$ ), student waist circumference in 2019 was wider (male $9.48 \mathrm{~cm}$ larger; female $7.94 \mathrm{~cm}$ wider).

The distribution of body fat in the direction of centralization has appeared, and there has been a significant tendency to accumulate belly fat in students.

\subsection{Total thickness of 3 skin folds}

We measured 3 points A8: The right side of the umbilicus, I15: The midpoint of the back of the arm (right) and E6: The point below the inferior angle of scapula (right).

The total thickness of skin folds of male and female $43.75 \pm 19.25 \mathrm{~mm}$; and52.41 \pm $14.66 \mathrm{~mm}$, respectively. Thus, the total thickness of skin folds of female students is about $8.65 \mathrm{~mm}$ higher than that of male students, the difference is statistically significant with $\mathrm{p}<0.01$.

Compared with the research results of Nguyen Truong An (2004) [1] in the 15-19 age group, the total thickness of skin folds in male and female students increased significantly. 


\subsection{BMI index}

According to the classification scale of the United Nations Subcommittee on Nutrition applied to Asians (1988), the nutritional status of first-year students of Hanoi Medical University is at normal level, accounting for a high proportion.

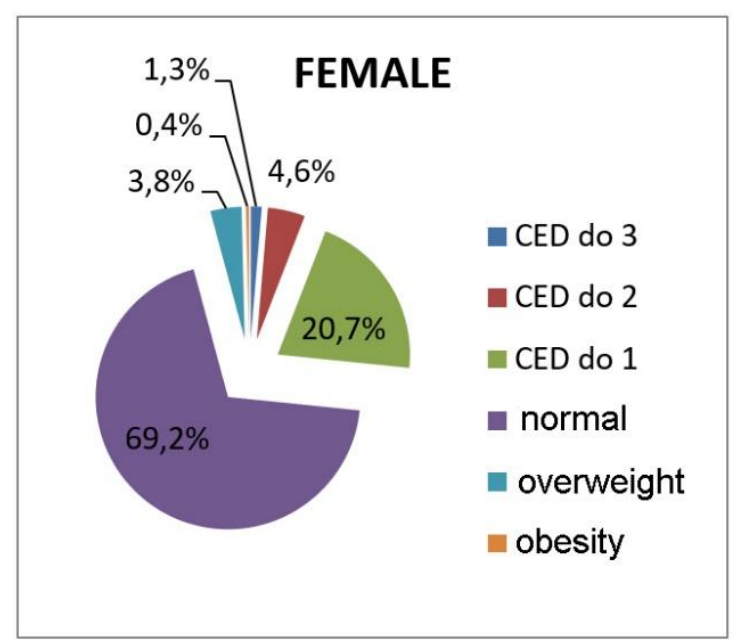

However, the percentage of students falling into a lack of energy on a regular basis is still significant, accounting for $26.6 \%$ for girls and $14.0 \%$ for men; overweight and obesity were not significant with $4.2 \%$ in female and $7.5 \%$ in male student.

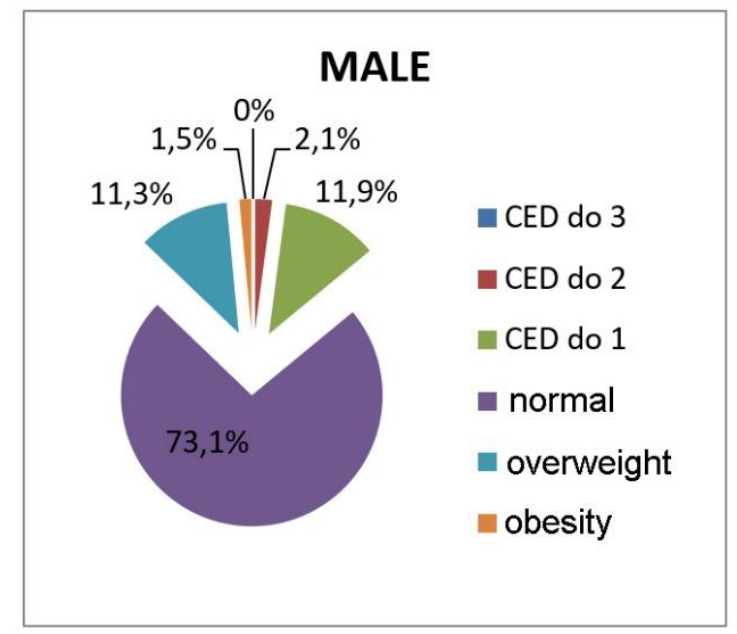

Chart 1: Classification of BMI in both sexes

Because this is a classification scale applied to Asians in general, it may be not accurate Vietnamese. Therefore, the chronic lack of energy (CED) among students is still quite high, and long-term monitoring is required during 6 years of study to be able to make accurate statements and make the right policies to improve the quality of life and improve nutritional status of medical students.

Table 2: Comparison of BMI of SV-2019 HMU with other authors' studies

\begin{tabular}{|c|c|c|}
\hline \multicolumn{1}{|r|}{ Gender } & Male & Female \\
\hline Tran Thi kim Thuc (2002) & $19,03 \pm 1,93$ & $19,65 \pm 1,79$ \\
\hline Do Dinh Xuan (2005) & $19,22 \pm 1,42$ & $19,47 \pm 1,76$ \\
\hline Le Dinh Van (2007) & $19,4 \pm 1,9$ & $19,3 \pm 1,7$ \\
\hline This study (2019) & $21,45 \pm 3,01$ & $20,03 \pm 2,39$ \\
\hline
\end{tabular}

* Compared with students in other regions in studies of the last decade, the nutritional status of first-year students at Hanoi Medical University (2019) is slightly better, still at the normal level. The difference between the sexes was statistically significant with $\mathrm{p}<0.01$.

* The dimensions of weight and height also contribute to the assessment of nutritional status, but we will analyze more in the assessment of physical morphology below.

\section{Some morphological and physical dimensions, indicators of HMU's students.}

\subsection{Weight:}


Table 3: Comparison of physical and morphological indicators of male students with other authors

\begin{tabular}{|c|c|c|c|c|c|c|}
\hline Authors & $\begin{array}{c}\text { HSSHNVN } \\
(1975)\end{array}$ & $\begin{array}{c}\text { Le Gia Vinh } \\
(1993)\end{array}$ & $\begin{array}{c}\text { Tran Thi } \\
\text { Xuan (1995) }\end{array}$ & $\begin{array}{c}\text { Do Dinh Xuan } \\
(2005)\end{array}$ & $\begin{array}{c}\text { Le Dinh Van } \\
(2007)\end{array}$ & $\begin{array}{c}\text { This study } \\
(2019)\end{array}$ \\
\hline Indicators & $\begin{array}{c}\text { Weight } \\
45,10 \pm 4,00\end{array}$ & $47,30 \pm 5,70$ & $48,80 \pm 3,80$ & $52,21 \pm 4,56$ & $52,5 \pm 6,1$ & $60,96 \pm 9,61$ \\
\hline $\begin{array}{c}\text { Standing } \\
\text { Height }\end{array}$ & $159,00 \pm 5,00$ & $162,90 \pm 5,40$ & $\begin{array}{c}162,10 \pm \\
6,60\end{array}$ & $164,79 \pm 5,76$ & $164,3 \pm 5,4$ & $168,47 \pm 5,73$ \\
\hline VNBT & $76,00 \pm 4,0$ & $78,90 \pm 6,0$ & $80,2 \pm 3,4$ & $80,71 \pm 3,39$ & & $80,17 \pm 6,87$ \\
\hline Pignet & $37,00 \pm 6,00$ & $36,70 \pm 7,50$ & $33,10 \pm 7,20$ & $32,42 \pm 6,35$ & & $27,34 \pm 14,27$ \\
\hline
\end{tabular}

Table 4:Comparison of physical and morphological indicators of female students with other authors

\begin{tabular}{|c|c|c|c|c|c|c|}
\hline $\begin{array}{r}\text { Authors } \\
\text { Indicators }\end{array}$ & $\begin{array}{c}\text { HSSHNVN } \\
(1975)\end{array}$ & $\begin{array}{c}\text { Le Gia Vinh } \\
(1993)\end{array}$ & $\begin{array}{c}\text { Tran Thi Xuan } \\
(1995)\end{array}$ & $\begin{array}{c}\text { Do Dinh Xuan } \\
(2005)\end{array}$ & $\begin{array}{c}\text { Le Dinh Van } \\
(2007)\end{array}$ & $\begin{array}{c}\text { This study } \\
(2019)\end{array}$ \\
\hline Weight & $43,00 \pm 4,00$ & $42,70 \pm 4,70$ & $45,90 \pm 4,80$ & $46,19 \pm 4,89$ & $44,9 \pm 4,4$ & $48,76 \pm 6,51$ \\
\hline $\begin{array}{c}\text { Standing } \\
\text { Height }\end{array}$ & $149,00 \pm 4,00$ & $155,10 \pm 4,50$ & $153,10 \pm 4,80$ & $153,92 \pm 5,07$ & $152,7 \pm 4,8$ & $155,99 \pm 5,65$ \\
\hline VNBT & $70,00 \pm 4,2$ & $76,50 \pm 5,2$ & $79,4 \pm 3,9$ & $77,69 \pm 3,97$ & & $72,02 \pm 6,38$ \\
\hline Pignet & $39,00 \pm 6,0$ & $35,9 \pm 6,8$ & & $30,76 \pm 7,4$ & & $35,21 \pm 11,15$ \\
\hline
\end{tabular}

In this study, male and female students had a significantly higher average weight than students in other studies. Compared with HSSHNVN (1975), the weight of male and female students in our study was much higher, (increased $15.9 \mathrm{~kg}$ in male and $5.8 \mathrm{~kg}$ in female). Compared with the author's study (2007), male students weigh $8.5 \mathrm{~kg}$ more and female students weigh $3.9 \mathrm{~kg}$ more.

The weight of students at Hanoi Medical University was heavier than previous studies, especially in male students, which might be the result of our country's developing economy and improved nutritional program in recent years.

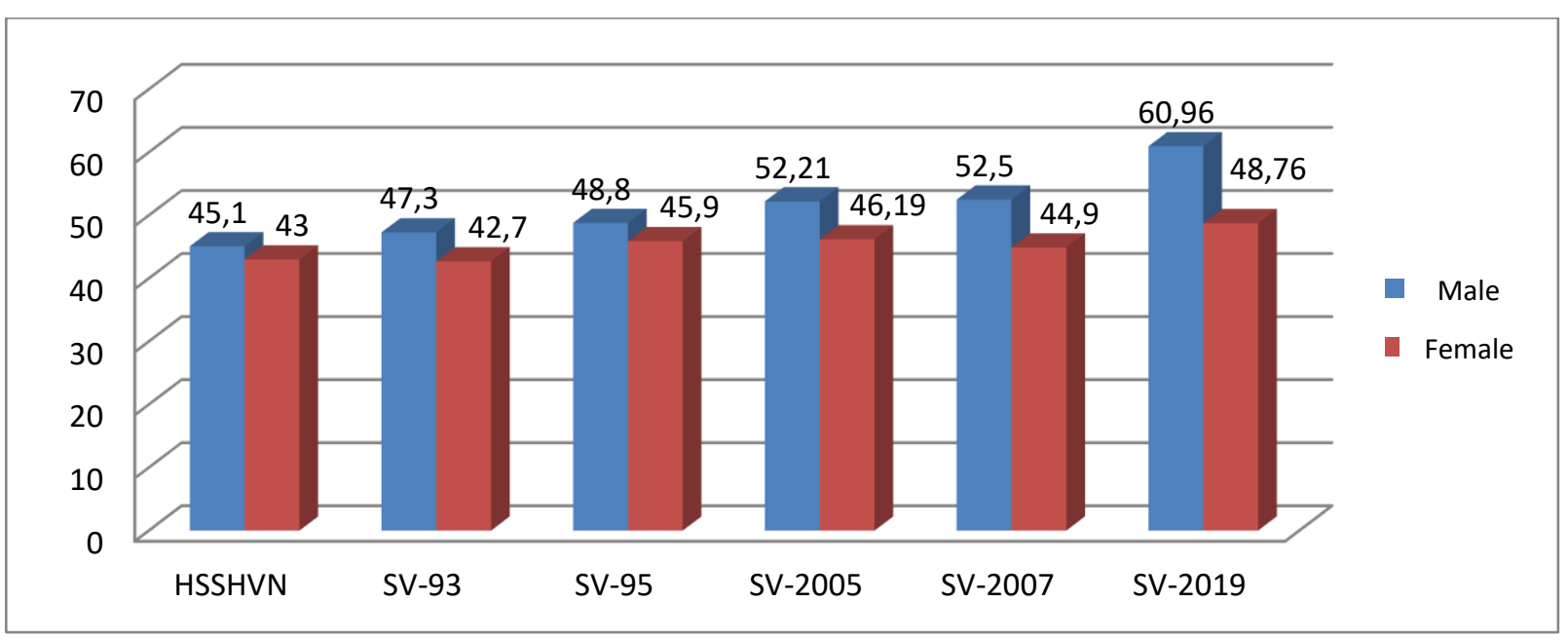

Chart 2: Comparison of average weight with other studies 


\subsection{Standing height:}

Compared with other studies, we found that the height of students in this study was much higher than in previous studies. Compared with HSSHNVN (1975), male students were $9.5 \mathrm{~cm}$ taller, female students were $7.0 \mathrm{~cm}$ taller. The increase in height of students in this study is consistent with other studies and the law of development: The following generations are constantly taller than the previous generations, especially after every decade.

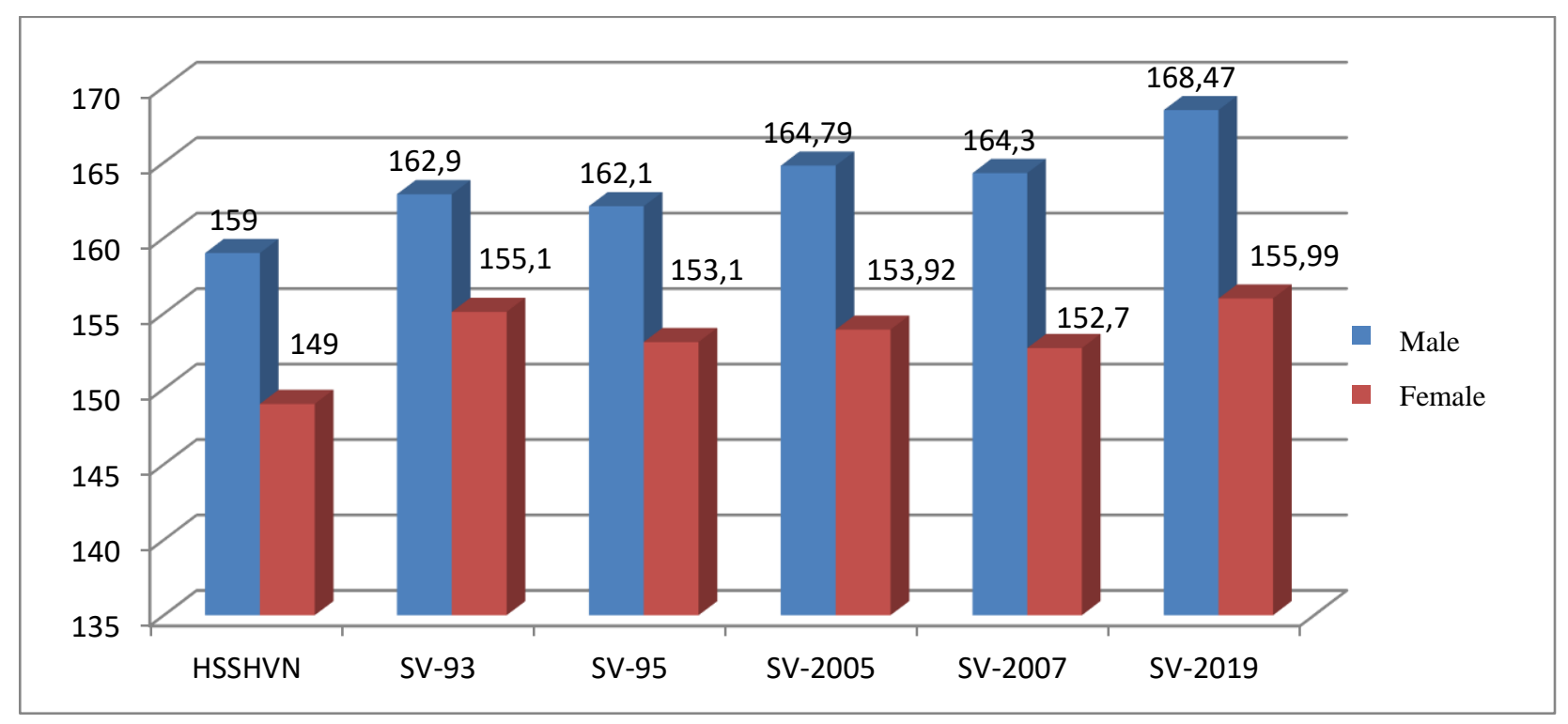

Chart 3: Comparison of average height with other studies

\subsection{Average chest circumference:}

The average chest circumference of male students in this study was similar to Do Dinh Xuan (2005) and Tran Thi Xuan (1995), but higher than other studies: HSSHNVN (1975) $(4.17 \mathrm{~cm}$ wider). The average chest circumference of female students was $2.02 \mathrm{~cm}$ larger wider than that of HSSHNVN (1975), but there is a decrease compared to studies from 1993 onwards. Thus, in terms of physical fitness, the development is somewhat slower and raises the question of whether it is necessary to further improve the exercise regime, especially for female students of Hanoi Medical University?

\subsection{Pignet:}

This index is similar to the average chest circumference, SV-2019 has a much lower index than HSSHNVN (1975), especially in male students. It proves that male students today have better physical strength than previous periods, however, in female students, their physical strength has not improved significantly.

\section{CONCLUSION}

1. There are significant differences in dimensions and indicators of physical morphology and nutrition between male and female students,

- The dimensions and fitness indexes of male students are much better than that of female students, especially in terms of height and weight, male students have grown faster than female students over the decades. Especially, the chest circumference and 
pignet index of female students have not improved significantly, which requires a reasonable policy on exercise and nutrition regimes for female medical students.

- There has been a tendency to accumulate fat in the abdomen, a tendency to centralize. The rate of chronic low energy in both sexes is still high, accounting for $26.6 \%$ in women and $14.0 \%$ in men.

2. The physical morphology of students tends to increase over time. According to the classification scale of the United Nations Subcommittee on Nutrition applied to Asians (1988), students of Hanoi Medical University had average weight.

\section{REFERENCES}

1. Nguyen Truong An (2004). Anthropometric evaluation of the physical, nutritional status and development of people in the Central region aged 15 years and older, Doctor of Medicine thesis, Hanoi Medical University.

2. Tran Thiet Son, Le Gia Vinh et al (1993). Some morphological characteristics of medical students in Hanoi, Morphology, 3, 1, pp. 19-22.

3. Tran Thi Kim Thuc (2004). Some physical morphological characteristics of students through health examination for admission to 10 universities and colleges in 2002-2003, Master's thesis of medicine, Military Medical Academy.

4. Nguyen Tan Gi Trong (1975). Biological constant of Vietnamese people, Medicine Publisher, Hanoi.

5. Le Dinh Van (2007). Height, weight, BMI and nutritional status of newly admitted students at Hue University, Journal of Military Medicine and Pharmacy, January 2009.

6. Do Dinh Xuan (2009). Physical morphological characteristics of students through examination for admission to Nam Dinh University of Nursing in 2005-2006, Journal of Military Medicine and Pharmacy, January 2009, 10-18.

7. WHO Expert Committee on Physical Status (1995), The use and interpretation of anthropometry, Report of a WHO Expert Committee, Geneva, 263-406.

8. Robert.C. Weisell (2002). Body mass index as an indicator of obesity. Asia Pacific.J. Clin. Nutr, 11, 681-684.

9. Michel Sempe, Guy Pedron (1979). Auxologie methode et sequences, Edit pour Theraplix, Paris. 